\title{
CONCEPÇÃO DE CIDADE/URBANO NO ENSINO DE GEOGRAFIA: ELEMENTOS PARA ANÁLISE
}

\author{
Rosana Alves Ribas Moragas - Departamento de Geografia - CAJ/UFG - \\ rosanarmoragas@yahoo.com.br - Rua Salgado Filho, 1009 - Setor Planalto -Jataí/GO
}

Resumo

O intuito deste artigo é uma tentativa de resgatar como o tema cidade/urbano vem sendo abordado no ensino de Geografia da Educação Básica. Para desenvolver essa análise propomos a seguinte estrutura: algumas considerações iniciais a respeito da transposição didática; um resgate teórico em obras que tratam a temática; bem como, tentar traçar elementos para elucidar de que forma o ensino de Geografia e, mais especificamente, o estudo da cidade/urbano contribui para a formação da cidadania.

Palavra-chave: cidade/urbano; ensino de Geografia; cidadania.

\section{Abstract}

City/Urban conceptions in Geography teaching: elementts for analysis

This article aims to unfolds how the theme city/urban has been pointed out in the Geography Basic Teaching. In other to develop this analysis, the following structure was presented: Some initial acknowledgements about didatics; a theorical support of literature concerning theme; the search for elucidatory elements in relatiion to both Geography teaching, city/urban studies and their contribution to citizenship formation.

Keywords: city/urban; Geography teaching; citizenship. 


\section{1 - A importância da transposição didática}

Antes de iniciarmos a temática propriamente dita, ou seja, a cidade e o urbano no ensino de Geografia, teceremos alguns comentários, ainda que breve, a respeito da transposição didática ou da relação entre uma ciência e a matéria de ensino (Cavalcanti, 1998) ou ainda, passagem do saber "universitário" para o saber "ensinado" (Simielli, 2001), por considerarmos importante alguns apontamentos a respeito.

Compartilhamos com as idéias e preocupações de Simielli (2001), no sentido de estabelecer diferenciação entre o saber universitário e o saber ensinado pelos professores, do ensino fundamental e médio, e também entre o saber ensinado e aquele realmente aprendido (teoria da aprendizagem significativa- Ausebel) . Para a autora, é necessário que se faça "uma transposição didática que nem vulgarize nem empobreça o saber universitário", mas sim que o construa de forma diferenciada, com o intuito de atingir o público escolar.

Simielli (2001), nos mostra também que esse saber universitário/acadêmico deve se adaptar/ajustar à capacidade mental dos alunos, respeitando as diferenças de domínio cognitivo, conforme argumenta:

O saber universitário apresenta-se sob a forma de peças de um quebra-cabeça sem uma imagem coerente na qual ele é multiplicado, separado, deixando ao observador a possibilidade de construir várias imagens. É a partir desse saber universitário que um saber ensinado deve ser elaborado, reconstruído, reorganizado.(Simielli, 2001:92)

Outra autora que demonstra preocupação com a transposição didática no ensino de Geografia é Cavalcanti (1998), abordando a questão do ponto de vista da complexidade existente entre ciência e matéria de ensino, pois as duas se constituem em uma unidade, mas não são idênticas. Neste sentido, esclarece:

A ciência geográfica constitui-se de teorias, conceitos e métodos referentes à problemática de seu objeto de investigação. A matéria de ensino Geografia corresponde ao conjunto de saberes dessa ciência, e de outras que não têm lugar no ensino fundamental e médio como Astronomia, Economia, Geologia, convertidos em conteúdos escolares a partir de uma seleção e de uma organização daqueles conhecimentos e procedimentos tidos como necessários à educação geral. (Cavalcanti, 1998:9) 
Essa distinção não se dá apenas na dimensão lógico-formal, mas também nos aspectos "pedagógicos, epistemológicos, psicocognitivos, didáticos", pois objetiva "a formação da personalidade dos alunos".

A partir de então, Cavalcanti sintetiza:

Não basta, portanto, aos que se dedicam à docência e à investigação de questões relacionadas com o saber geográfico escolar, o domínio de conteúdos e métodos da ciência geográfica. É preciso que se considere, além disso, a relação entre essa ciência e sua organização para o ensino, incluindo aí a aprendizagem dos alunos conforme suas características físicas, afetivas, intelectuais, socioculturais.(Cavalcanti, 1998:10)

Analisando ainda mais a questão, Simielli (2001) enfatiza "que mais que uma transposição didática, é necessário fazer uma verdadeira reconstrução do saber geográfico sobre bases parcialmente diferentes", porque o conjunto dos objetivos, dos meios, e finalidades da Geografia é distinto, seja na universidade, no ensino básico ou médio.

Para essa autora, essa reconstrução deve ser realizada em vários níveis:

1. reconstrução no nível dos programas oficiais;

2. reconstrução no nível do professor;

3. reconstrução no nível da lição;

4. reconstrução no nível do aluno

Reforçando essa idéia, vale transcrever as palavras de Azambuja:

...Neste caso, o conhecimento não é um conjunto de informações a serem repassadas aos alunos, mas sim um saber a ser reconstruído pelos alunos e professor na relação do universal com o particular, do saber construído pela ciência com o saber e as referências de cada individualidade...(Azambuja, 2003:6)

Simielli (2001) acrescenta a essa problemática do saber acadêmico/universitário e do saber ensinado na escola básica, a forma como se encaminha as diversas disciplinas da Geografia na universidade, principalmente a cartografia, ou seja, com um tratamento, na maioria das vezes, direcionado à pesquisa, ao planejamento em detrimento do ensino 
fundamental e médio. Neste sentido, é salutar que pensemos nesta perspectiva também para a temática da cidade e do urbano.

\section{2 - Resgate teórico: cidade/urbano no ensino de Geografia}

Vários autores da ciência geográfica têm trabalhado com a questão da cidade e o ensino de Geografia, ou melhor, como se pode desenvolver o tema cidade no contexto do ensino fundamental na área de Geografia. Vamos nos ater, neste momento especificamente, em duas obras, um primeiro momento na de Cavalcanti (2002) e, posteriormente, em Schäffer (1999).

Cavalcanti (2002) vai argumentar em suas idéias a importância de se estudar a temática da cidade nos conteúdos de Geografia, por dois motivos, um por se tratar de uma espacialidade específica com suas multiplicidades de aspectos e características próprias, outro como desenvolvimento de habilidades, valores e condutas para a vida cotidiana, contribuindo neste sentido para a formação da cidadania. Aliás, outros autores também vão sempre fazer menção aos estudos da cidade no ensino de Geografia como uma busca de se conquistar a cidadania. Esse objetivo também está explícito nas diversas propostas curriculares para o ensino de Geografia, sejam elas, federais, estaduais ou municipais, do ensino fundamental ou do nível médio.

Neste sentido analisaremos, mais particularmente, o que nos retrata Cavalcanti (2002) a esse respeito. Para a autora,

O ensino de Geografia contribui para a formação da cidadania através da prática de construção e reconstrução de conhecimentos, habilidades, valores que ampliam a capacidade de crianças e jovens compreenderem o mundo em que vivem e atuam, numa escola organizada como um espaço aberto e vivo de culturas. O exercício da cidadania na sociedade atual, por sua vez, requer uma concepção, uma experiência, uma prática comportamentos, hábitos, ações concretas - de cidade. (Cavalcanti, 2002:47)

Essa crença na importância da cidade para a constituição da cidadania se estabelece para a presente autora, como para a maioria dos autores que escrevem sobre a cidade e ou urbano, pelo fato da crescente vida nas cidades desde o século XIX, tornando-se assim um fato mundial.Cada vez mais um número maior de pessoas passam a morar nas cidades. Por 
Ztinerarius

eflectionis
Revista Eletrônica de Educação do Curso de Pedagogia

do Campus Avançado de Jataí da Universidade Federal de Goiás

[Vol I - n.2 ] [jan/jul] [ 2006 ]

ISSN: $1807-9342$

isso a cidade é caracterizada como uma aglomeração de pessoas e de seus objetos. (Carlos,1992).

A cidade é o locus onde se expressam todas as nossas contradições sociais. É a dialética do estar vivo, do querer e do não querer. Parece-nos que na cidade todos os problemas são evidenciados, viram notícias, todas as mazelas sociais são mais profundas, pois no campo elas também existem, mas na cidade há um caráter próprio dela que é o de aglomeração, enquanto no campo é o da dispersão.

De acordo com Santos (1997:22) apud Ribas (1998).., "Os homens vivem cada vez mais amontoados lado a lado em aglomerações monstruosas, mas estão isolados uns dos outros"... gerando com isso uma certa passividade em relação às decisões que atingem diretamente sua vida. Nas grandes metrópoles isso vem ocorrendo com maior ênfase, dando lugar muito mais ao consumidor do que ao cidadão.

Retomando novamente Cavalcanti (2002), a respeito da temática enfocada, ela nos deixa claro que “...A escola, porém, não é a única instância de formação de concepções e práticas da cidade, habilidades básicas no exercício da cidadania...”, ou seja, há outras instâncias propiciadoras dessa formação, tais como, as práticas de organização e gestão da cidade, bem como as experiências vivenciadas no dia-a-dia pelos próprios alunos. A escola na sua visão é lugar privilegiado, pois é síntese de "encontro e confronto" das diversas concepções e práticas da cidade (saber científico e saber cotidiano).

Na concepção de Cavalcanti (2002), a escola, ao optar por trabalhar com o eixo temático cidade/urbano, tem que propiciar atividades em que os alunos percebam que existem "diferentes imagens da cidade: cotidianas e científicas", que podem se confrontar. Seguindo a mesma linha de raciocínio, a autora vai recorrer a Bernet (1997), para esboçar três imagens da cidade: sendo a primeira, a imagem subjetiva que cada indivíduo cria do seu meio; a segunda, objetiva, global e profunda que as instituições educativas utilizam; e a terceira, a imagem da cidade a ser construída, ou seja, a cidade que se deseja ter, baseada também na utopia, na imaginação, para contrapor assim com a realidade vivida e a partir de então criar elementos para a construção de uma cidade melhor para todos.

$\mathrm{Na}$ abordagem de Cavalcanti (2002), a imagem e a prática de indivíduos na cidade estão vinculadas, por isso o entendimento de como se estabelece a imagem e a prática da cidade hoje se faz necessário no ambiente escolar. Portanto, é imprescindível, 
com os conteúdos sistematizados e experiências curriculares na aula de Geografia e o que resulta desse encontro do ponto de vista da aprendizagem e do desenvolvimento intelectual, social e afetivo do aluno. (Cavalcanti, 2002:48)

Outra autora que vai abordar o tema cidade/urbano nas aulas de Geografia é Schäffer (1999), seguindo uma linha de raciocínio que vai desde a apresentação da cidade nos estudos de Geografia, bem como nos livros didáticos, à pela indagação do porquê estudar a cidade nas aulas de Geografia e como está o estudo desse tema em algumas propostas curriculares da década de 80 .

Schäffer (1999) vai fazer uma revisão geral de como o tema cidade esteve presente nos diversos momentos da ciência geográfica. $\mathrm{Na}$ Geografia chamada tradicional, este tema teve relegado a segundo plano, pois os estudos que tiveram mais ênfase foram sobre os fenômenos da natureza e estudos agrários. Portanto, não teve também grande repercussão no ensino de Geografia. As referências sobre cidade nos livros didáticos dessa época estavam baseados em aspectos históricos da cidade, posição, sítio urbano, população e atividades fundamentais, considerando a cidade nos seus elementos mais formais e funcionais.

Um segundo momento, presente na ciência geográfica, destacado pela referida autora, vem após a Segunda Guerra Mundial com muitas transformações mundiais, oriundas do processo de reorientação do capitalismo. Momento este que valorizou e muito o planejamento territorial, acreditando que o mesmo serviria para promover o desenvolvimento e sanar as desigualdades socioespaciais. Essas transformações mundiais, como o crescimento populacional, o êxodo rural, constituiu a importância de se estudar a cidade e a população, para atender aos interesses do planejamento estatal e ao acúmulo do capitalismo.

Segundo Schäffer (1999), a cidade foi vista, nesse momento, "como um sistema e os problemas que se colocavam para seu "desenvolvimento" ou "progresso" como desequilíbrios ou disfunções do sistema". Os estudos sobre essa temática nesse período se destacaram pela diversidade de teorias, de modelos de estrutura urbana, e também do uso de modelos estatísticos e matemáticos, com o objetivo de quantificar, classificar e descrever a cidade do ponto de vista lógico matemático.

Toda essa diversidade teórica e instrumental esboçada acima, de acordo com Schäffer (1999), não foi repassada ao todo para o ensino fundamental, privilegiando alguns itens, tais como, rede urbana,funções urbanas, estrutura e uso do solo.

Como aponta Schäffer (1999), no final da década de 70, houve no Brasil a tão conhecida renovação da Geografia, fruto de novas formas de análise do ponto de vista teórico 
Utinerarius

Peflectionis
Revista Eletrônica de Educação do Curso de Pedagogia do Campus Avançado de Jataí da Universidade Federal de Goiás [Vol I - n.2 ] [jan/jul] [ 2006 ]

e metodológico, influência de outras ciências principalmente a sociologia e a economia, em que a cidade passa a ser estudada pelo viés das relações sociais de produção que se estabelecem em uma sociedade contraditória, dividida em classes sociais antagônicas. Nessa concepção, cidade e campo não são mais divergentes e sim um par do mesmo processo de produção. A urbanização é tida como um processo importante para entender a cidade e o seu contexto. Nesse movimento de renovação geográfica, novos temas passaram a ser o foco de análise da cidade/urbano, renda e uso do solo, produção da moradia/habitação, segregação social/espacial, acessibilidade à infra-estrutura urbana, agentes produtores do espaço urbano (Estado, capital e a sociedade). A Geografia urbana passa a entender a cidade do ponto de vista social, e que o indivíduo, o morador, o aluno é o agente de produção e transformação da mesma.

Segundo Schäffer (1999), essa nova concepção de se estudar a cidade repercutiu nos livros didáticos mais rápido, onde passaram a abordar temas da relação cidade-campo, a produção do espaço urbano realizada pelos diversos agentes produtores, a questão do uso do solo urbano, o cotidiano das cidades, onde são expressas, de forma mais latentes, as contradições sociais e a degradação do meio ambiente.

Embasada em observações realizadas nos livros didáticos atuais, Schäffer (1999) mostra que as principais linhas de pesquisa geográfica abordando o estudo da cidade, fazemse presentes nessas obras. Argumenta ainda que, as transformações econômicas, sociais, políticas e culturais mais recentes, em conjunto com as novas concepções pedagógicas, vêm refletindo no ensino de maneira geral e no tema específico da cidade. Neste sentido, atualmente a formação integral do aluno está centrada não só no aspecto cognitivo, o saber, mas também nos aspectos comportamentais, ou seja, saber fazer, e também nas atitudes e valores, exigindo dos professores que trabalham com a temática urbana uma visão mais ampla para pensar e planejar a mesma.

Considera Schäffer (1999) que o motivo de se estudar a temática da cidade /urbano no ensino de Geografia, pressupõe em respondermos a uma pergunta mais ampla e também que a antecede, que é, por que estudar Geografia? Para a autora, o estudo desse tema, ou de outras unidades de ensino, deve estar atrelado ao posicionamento do professor, desde o domínio de conhecimentos específicos de sua disciplina, à clareza dos seus objetivos, que vâo ocasionar uma abordagem sobre a cidade, de forma descompromissada, só porque faz parte do conteúdo e porque está no livro didático ou de forma envolvente, que faça com que o aluno reflita, critique, posicione-se, sinta-se parte do processo de produção e reprodução da cidade. 
Ltinerarius

eflectionis
Revista Eletrônica de Educação do Curso de Pedagogia

do Campus Avançado de Jataí da Universidade Federal de Goiás [Vol I - n.2 ] [jan/jul] [ 2006 ]

ISSN: $1807-9342$

Neste mesmo estudo, Schäffer (1999) faz análise de quatro propostas curriculares vigentes na década de 80, sendo uma da Secretária da Educação do Rio Grande do Sul, no início dos anos 80 e as outras três, respectivamente, da UNIJUÍ (1984), da Secretária de Educação do Estado do Rio de Janeiro (1988) e da Secretária de Educação do Estado de São Paulo (1988). Segundo a autora, a primeira proposta (SEC/RS) se distingue bastante das três posteriores, pois se enquadra nos pressupostos gerais da Lei 5692/71, e em toda a conjuntura desse período histórico, como a noção de cidadania, no sentido de ajustar o aluno para atender ao sistema político/econômico/social vigente. A cidade nessa proposta se apresenta "como sistema, em uma soma de partes, como formas e funções alheias à ação do indivíduo".

As três propostas posteriores (UNIJUÍ, SEC/RJ e SEC/SP), de acordo com Schäffer, podem ser enquadradas numa mesma concepção teórica metodológica, salvo as particularidades de cada uma. Assim sendo, o estudo da cidade, "não mais se baseia na noção de sistema, mas de totalidade, de espaço socialmente construído e, portanto, historicamente determinado".Distinguindo-se da proposta anterior, também nos aspectos de educação para formação da cidadania, agora entendida como formadora de um aluno crítico, reflexivo, atuante, capaz de se perceber agente da produção do espaço. A presente autora, avalia que há diferenças nestes dois blocos de propostas analisadas, diferenças que correspondem tanto à concepção de cidade/urbano, como aos conteúdos e procedimentos para desenvolvem esse tema em sala de aula.

Schäffer (1999) sintetiza que o estudo da cidade/urbano no ensino de Geografia não pode ter um modelo único, pois atualmente há uma gama de complexidade e diversidade que envolve essa temática, juntamente com as novas concepções didático-pedagógicas e também as novas propostas curriculares presentes em todo o país.

Como já mencionamos anteriormente neste texto, o tema cidade/urbano já vem há algum tempo fazendo parte dos conteúdos curriculares do ensino de Geografia de várias propostas educativas, sejam elas federais, com os Parâmetros Curriculares Nacionais; estaduais, ou municipais, tendo como exemplo as cidades de Porto Alegre/RS e Goiânia/GO, que desenvolveram, na sua proposta político-pedagógica "Escola para o século XXI", o eixo temático cidade-cidadania como proposta para um todo e não apenas para o ensino de Geografia, evidenciando o contexto interdisciplinar de se estudar a cidade e a sua importância no meio escolar, caracterizando, também, a sua contribuição para a formação da cidadania social e não apenas jurídica do educando. 
Há um número considerável de autores da ciência geográfica, relacionados ou não com a temática de ensino, que abordam a relevância do ensino de Geografia para a formação do cidadão, sendo que a maioria desses escritos oficiais (propostas curriculares) ou não-oficiais acreditam que a escola, numa estância maior, e a Geografia, na sua especificidade curricular, podem contribuir muito na formação de alunos cidadãos. Podemos destacar alguns desses trechos, a título de ilustração:

A Geografia é uma área de conhecimento comprometida em tornar o mundo compreensível para os alunos, explicável e passível de transformações. Neste sentido, assume grande relevância dentro do contexto dos Parâmetros Curriculares Nacionais, em sua meta de buscar um ensino para a conquista da cidadania brasileira. As temáticas com as quais a Geografia trabalha na atualidade encontram-se permeadas por essa preocupação. (Brasil, 1998:26)

...ou ensinar uma geografia crítica, que forme criticamente a criança, voltada, portanto, para seu desenvolvimento e sua formação como cidadão. Uma geografia preocupada desde cedo com o papel que estas crianças/trabalhadores terão no futuro deste país. Uma geografia que possibilite às crianças, no processo de amadurecimento físico e intelectual, irem formando/criando um universo crítico que lhes permita se posicionar em relação ao futuro, que lhes permita finalmente construir o futuro. (Oliveira, 1991:144)

Acreditamos que o caminho para a construção da cidadania, no seu sentido pleno,ou seja, na formação de opinião crítica e de participação na construção social não configura como um caminho fácil/simples, mas sem dúvida um caminho que deva ser trilhado, principalmente, mas não exclusivamente pela escola, e que no entanto a Geografia, com todo o seu arcabouço teórico-metodológico, enquanto ciência acadêmica ou disciplina escolar, pode contribuir e muito nessa caminhada, seja nos conteúdos relacionados à cidade/urbano ou a qualquer outra unidade temática.

\section{3 - Referências Bibliográficas}


AZAMBUJA, L. D. A construção social do conhecimento na Geografia escolar. In: Espaços da Escola, Ijuí: Editora Unijuí, ano12, n. 47, p. 5-10, jan./mar. 2003.

BRASIL, Secretária de Educação Fundamental. Ministério da Educação e Cultura. Parâmetros Curriculares Nacionais: geografia. Brasília, MEC/SEF, 1998.

CALLAI, H. C. O ensino de geografia: recortes espaciais para análise. In: CASTROGIOVANNI, A. C. et al. (Orgs.). Geografia em sala de aula, práticas e reflexões. Porto Alegre: associação dos Geógrafos Brasileiros, Seção Porto Alegre, 1999.

CARLOS, A. F. A. A cidade. São Paulo: Contexto, 1992.

CAVALCANTI, L.S. Geografia, escola e construção de conhecimentos. Campinas: Papirus, 1998.

Geografia e práticas de ensino. Goiânia: Alternativa, 2002.

DAMIANI, A. L. A geografia e a construção da cidadania. In: CARLOS, A. F. A. et al. (Orgs.). A geografia em sala de aula. São Paulo: Contexto, 2001.

KOHN, N. B. P. O estudo da cidade nas aulas de geografia do ensino fundamental: um jogo que constrói cidadãos. In: Espaços da Escola, Ijuí: Editora Unijuí, ano12, n. 47, p. 21-24, jan./mar. 2003.

OLIVEIRA, A. U.(Org.). Para onde vai o ensino de geografia? São Paulo: Contexto,1991.

OLIVEIRA, L. O ensino/aprendizagem de geografia nos diferentes níveis de ensino. In: OLIVEIRA, A. U.; PONTUSCHKA, N.N.(Orgs.). Geografia em Perspectiva. São Paulo: Contexto, 2002.

PONTUSCHKA, N. N. A geografia: pesquisa e ensino. In: CARLOS, A. F. A (Org.). Novos caminhos da geografia. São Paulo: Contexto, 1999.

RIBAS, R.A. Subutilização dos espaços públicos de lazer: o caso do parque das andorinhas- Presidente Prudente-SP. Presidente Prudente,1998. Dissertação (Mestrado) Universidade Estadual Paulista.

SCHÄFFER, N. O. A cidade nas aulas de geografia. In: CASTROGIOVANNI, A. C. et al. (Orgs.). Geografia em sala de aula, práticas e reflexões. Porto Alegre: associação dos Geógrafos Brasileiros, Seção Porto Alegre, 1999.

SIMIELLI, M. E. R. Cartografia no ensino fundamental e médio. In: CARLOS, A. F. A. et al. (Orgs.). A geografia em sala de aula. São Paulo: Contexto, 2001. 